\title{
DISCURSO DE POSSE NA DIRETORIA DA FACULDADE DE DIREITO DA UNIVERSIDADE DE SÃO PAULO
}

\author{
Eduardo Cesar Silveira Vita Marchi \\ Diretor da Faculdade de Direito da Universidade de São Paulo
}

Local: Salão Nobre da Faculdade de Direito da Universidade de São Paulo Data: 09 de agosto de 2002, às $19 \mathrm{~h} 00$.

Magnífico Vice-Reitor, Professor Hélio Nogueira da Cruz;

Exma. Sra. Diretora, Professora Ivette Senise Ferreira;

Exmo. Sr. Professor José Carlos Moreira Alves, digníssimo decano da Congregação desta Faculdade e ministro da mais alta Corte de Justiça do País, a quem honrado agradeço a brilhante oração e as amáveis palavras de cumprimento, e com quem tenho tido, há quase vinte anos, o privilégio (também com sua dileta esposa; Dra. Evany) de manter calorosos laços de amizade;

Exmos. Srs. Diretores de Unidades e Institutos, Coordenadores de Comissões e Núcleos de nossa Universidade, bem como ilustres Dirigentes Universitários de outras Escolas; Dignos Representantes de Tribunais de outras Instituições, públicas ou privadas, do mundo jurídico;

Eminentes Professores, prezadas alunas e alunos, estimados funcionários;

Queridos familiares e diletos amigos;

Prezada Assistência, aqui presente, e que agora me houve;

Extremamente honrado, por alçar-me, no recinto venerando desta Academia, à direção da gloriosa Faculdade de Direito da Egrégia Universidade de São Paulo, desejaria, desde logo, manifestar alguns agradecimentos.

Em primeiro lugar, a nosso Magnifico Reitor, que aqui não pôde estar por razões de saúde, por confiar-me, com a dignidade desta investidura, a direção de nossa Faculdade.

Em seguida, à Douta Congregação e aos Conselhos Departamentais, nas pessoas de seus professores, representantes do corpo discente e dos funcionários, por me distinguirem, com seu sufrágio.

E, por fim, à Professora Ivette, que neste momento se despede do honroso cargo, pela exemplar gestão exercida por quem foi a primeira Diretora na história de nossa Faculdade. 
Minhas Senhoras e Meus Senhores.

Corria a década de trinta. Terminadas as aulas, o Bar "Ponto Chic" no Largo do Paissandu, estava, como de costume, repleto de estudantes de Direito do Largo de São Francisco. Dentre eles, um, aliás - Casemiro Pinto Neto -, apelidado de "Bauru" pelos colegas, dado o nome da cidade onde nascera, pedia ao garçom, mais uma vez, "o de sempre", isto é, um "sandwich", até então ignorado no cardápio, preparado com pão, rosbife (mais tarde, presunto), queijo derretido e tomate. Alguns dos seus colegas de mesa, já apreciadores da nova moda, ordenavam também "um Bauru" ao garçom.

Em outro canto do Bar "Ponto Chic", outra turma de estudantes do Largo conversava animadamente. Dentre eles, Ubirajara Martins, que, por usar barba imponente e bigodinhos de pontas aguçadas, muito em voga na época, era conhecido nas Arcadas pela alcunha de "Pic-Pic". Isto se explicava pelo seu constante uso de uma tesourinha para aparar a barba e o bigode. Figura conhecida entre os colegas, por ser também jogador de futebol amador do velho Palmeiras da Floresta, era constantemente saudado, evocando-lhe o apelido: "É o pic-pic, é o pic-pic!"

Consumido o primeiro fornecimento de cerveja e dadas as reduzidas dimensões das geladeiras do local, os estudantes deviam aguardar mais ou menos meiahora até que, adicionada nova barra de gelo, fosse refrigerada a segunda rodada. Acompanhando ansiosamente o avanço do relógio, chegado o grande momento tão desejado, os estudantes, em coro, punham-se a cantar: "Meia-hora, meia-hora: é hora, é hora!".

Naquela época, por outro lado, a Faculdade recebera a visita de um Rajá, chamado Timbum (ou algo parecido), proveniente da região de Kapurtala, na Índia. A insólita visita, aliada à sonoridade do nome do Rajá indiano, trouxe aos estudantes a oportunidade de incorporar, no fim de seus cantos e hinos, um novo remate: " $R \dot{a}, j a \dot{a}$, tim, bum!"

Pouco a pouco, no "Ponto Chic", os estudantes, geração após geração, iam passando de boca em boca estes seus gritos de guerra e brincadeiras, dentre os quais aqueles, consolidados no refrão: "É pic-pic, é pic-pic; meia-hora; meia-hora, é hora, é hora; rá, já, tim, bum!"

Das mesas do "Ponto Chic" às festas de aniversário nas casas dos estudantes não faltou muito. Daí o tradicional "canto do pic-pic" difundiu-se por outras festas em São Paulo, e, em seguida, estendeu-se a todo o País. Ainda, hoje, pois, em cada comemoração de aniversário, evoca-se - sem o saber - um canto dos estudantes das Arcadas.

Esta história verdadeira, embora não muito conhecida entre nós, ilustra bem a influência de nossa Academia até mesmo nos pormenores do quotidiano nacional.

Acima de aspectos menores, a ascendência desta Escola tem-se manifestado principalmente, como é notório, em dois planos fundamentais: o de sua vocacão política, de um lado, e a científico-jurídica, de outro. 
É conhecida sua tradição política, sendo dificil encontrar qualquer grande causa da nacionalidade em que as Arcadas não tenham feito sentir, quer diretamente, quer pela ação de seus membros, estudantes e bacharéis. Esta Academia, como já se disse, tem sido uma Escola não-só de Direito, como também de estadistas.

Já deu ao País dez presidentes da República, quarenta e cinco governadores da Província depois Estado de São Paulo, e uma plêiade de importantes parlamentares, legisladores e administradores públicos. Prova da assertiva é a composição do atual Governo: cinco Ministérios acham-se em mãos de ex-alunos, como, por exemplo, o das Relações Exteriores, ocupado pelo nosso eminente professor Celso Lafer.

Vê-se, pois, por esta notícia, como nossa Faculdade, em muitas ocasiões, tem orientado os destinos políticos de nossa Pátria através da atuação de seus filhos.

No concernente à tradição científico-jurídica, é também conhecido o primado, em nosso País, exercido pelos estudos aqui produzidos, e consubstanciados em brilhantes livros, manuais e tratados, artigos e ensaios científicos de lavra de nossos professores. No mesmo sentido, é também sensível a superioridade de nosso ensino jurídico, comprovada pelo êxito de nossos bacharéis nos concursos públicos e na acirrada luta pelos melhores cargos no mercado de trabalho. São inúmeros, no passado e no presente, os exemplos de ilustres juristas, magistrados, promotores, advogados e consultores jurídicos de empresas que aqui se formaram.

É, pois, grandissima honra, para nós, poder dirigir uma Escola com papel, quer no plano jurídico, quer no político, tão relevante na história passada, presente e esperamos - futura de nosso País!

Como já rezavam, no século dezenove, os antigos Estatutos do Visconde de Cachoeira, a vocação desta Escola sempre foi e ainda é a de formar "homens hábeis para serem um dia sábios magistrados e peritos advogados, de que tanto se carece" bem como "dignos deputados e senadores para ocuparem os lugares diplomáticos e mais empregos do Estado"

Percebe-se, assim, de modo claro, que nossa Faculdade vem - e continuará - cumprindo fielmente aquela missão e função visadas por aqueles velhos estatutos. nossa Escola.

Referimo-nos aqui, mais de uma vez, à dupla vocação inspiradora de

Sem esquecer - é claro - a destinação política, inspiradora da luta pela liberdade, pelos direitos fundamentais do homem, pelo civismo e cidadania e pela renovação das idéias, devemos reconhecer, especialmente diante dos desafios do mundo de hoje, que a vocação primária de nossa Faculdade é de caráter científico-jurídico, pressuposto, aliás, da outra, a política. Só poderemos oferecer "hábeis" homens públicos ao futuro do País se, antes, nos dedicarmos, de corpo e alma, à sua formação jurídica, buscando sempre a excelência na pesquisa e no ensino, tradicional em nossa Academia.

Em última análise, pois, o espírito científico deve sempre prevalecer sobre interesses politicos, econômicos ou outros de qualquer natureza. 
E não poderia ser de outro modo. O dístico, esculpido no brasão de nossa Universidade, preceitua: “Scientia, vinces!" ("Vencerás pela Ciência!”).

Ele também se aplica à Faculdade de Direito.

Venceremos pelo uso do chamado "método científico": é necessário, como fazia Leonardo da Vinci - considerado por isso mesmo o primeiro cientista do mundo moderno -, experimentar, e eventualmente comprovar, de modo exaustivo, as várias hipóteses para uma tese. E, para isto, exige-se tempo, é claro. Diante de um problema jurídico - teórico ou prático - impõe-se, pelo método científico, que o jurista examine e comprove as várias hipóteses de solução, consultando atentamente toda a literatura jurídica dos países onde o problema (ou questão semelhante) se apresente. Para isto, como se disse, precisa-se de tempo. Por tal motivo, no ambiente das ciências juridicas, a cumulação da atividade profissional com a carreira universitária não é o melhor caminho, que não existe, por exemplo, na Alemanha, Japão, Inglaterra ou Estados Unidos.

Munidos desta vocação científica básica, devemos, pois, lutar por um ensino jurídico de qualidade, e pela manutenção do primado de nossa Faculdade dentre as escolas de Direito do País.

Neste sentido, podem-se aqui apresentar algumas idéias ou sugestões, a serem depois discutidas e avaliadas. Ei-las:

- Grupos de Monitoria e Pesquisa. A aula ministrada "ex cathedra" não é o único modo de ensinar. Pode-se também aprender sem que o aluno tenha que fazer infindáveis anotações hauridas em aula expositiva. Cumpre, pois, incentivar as aulas práticas com grupos de monitoria e pesquisa, caracterizados pela participação ativa dos alunos e não-só do professor.

- Conjugação de Exames Orais aos Exames Escritos. O recurso apenas à prova escrita para avaliação dos estudantes não basta. Nosso futuro bacharel deve saber redigir bem; todavia, deve também expressar-se oralmente com fluência, tranqüilidade, exatidão, rapidez de memória e de raciocínio, quer diante de bancas de concurso, quer na atividade profissional diante dos participantes de uma audiência. Para isto servem, na formação e aprendizado de nossos alunos, os exames orais.

- Bolsas de Iniciação Científica. Visando proporcionar boa formação básica a nossos alunos, precisamos pleitear o aumento do número de bolsas ora disponíveis, recorrendo à ajuda financeira tanto de entes públicos, como a FAPESP e o CNPq, quanto (e eis aqui a novidade) de grandes bancas de advocacia, do empresariado e da indústria, através de doações por eles oferecidas. Cresceria, assim, notavelmente, a contribuição de nossa Faculdade para a formação de futuros "homens hábeis" para a Nação.

- Formação básica e Mercado de Trabalho. A Universidade, especialmente a pública, vive hoje um impasse: deverá ou não acompanhar "pari passu" 
as transformações do mercado? A melhor resposta, quer de muitos professores, quer de especialistas fora da Universidade, é inteiramente negativa. Curiosamente, aliás, é entre os especialistas em mercado de trabalho, e não entre os acadêmicos e coordenadores de cursos jurídicos, que parece reinar unanimidade contra esta tendência atual.

As universidades, sobretudo as públicas, não podem ficar, dizem eles, dependendo das exigências do mercado. Do contrário, elas deveriam contínua e rapidamente incluir e excluir disciplinas, de acordo com as novas necessidades.

Isto não é só impossivel, como também indesejável. Impossível, pois o processo de transformação do mundo profissional ou do trabalho é exageradamente veloz e acelerado. Indesejável, porque, assim procedendo, corre-se o risco de comprometer a capacidade de pensar, vale dizer, de crítica e reflexão do aluno.

Finalidade precípua da Universidade Pública deve ser, portanto, a de propiciar ao aluno uma formação básica e sólida, durante a quase totalidade dos anos do curso de graduação. Ensinar bem as disciplinas fundamentais da carreira jurídica já constitui enorme desafio e árdua tarefa.

Obtida sólida e consistente formação acadêmica, o diploma passa então a ser não um ponto de chegada, mas, ao contrário, um ponto de partida. Em outros termos, o atendimento às necessidades do mercado, vale dizer, a especialização e o conhecimento de disciplinas novas, devem ser buscadas pelo aluno, sobretudo durante o exercício da vida profissional.

Combatamos, pois, entre nós, o desprezo pelo tipo de formação acadêmica tradicional, fenômeno, aliás, cíclico no Brasil, como atestam os especialistas em ensino.

Concluindo este ponto: função da Universidade Pública, cómo alguém já disse, é a de atender não ao mercado, mas sim, à sociedade, vale dizer, ao País, considerando o que é melhor para o futuro do Brasil e não o que convém aos interesses privados de um ou outro setor do mundo do trabalho.

Não se pretende, com tudo isso, dizer que a Faculdade deva virar as costas para os novos e importantes problemas do atual mundo do trabalho e da atividade profissional.

Ao lado da concentração principal na formação básica do aluno, deve a Academia manter-se aberta à discussão destes novos problemas, de modo a oferecer talvez nos últimos dois anos do curso - novas disciplinas ligadas às grandes novidades do mundo jurídico atual.

É o caso, por exemplo, do Biodireito, da Defesa do Meio Ambiente, do Comércio Eletrônico, do Direito do Consumidor, da Informática Jurídica etc. Diante deste quadro, o melhor caminho parece o de combinar o modelo tradicional de ensino, de formação básica dirigida e controlada, com outro, de completa flexibilidade, sem qualquer imposição ao aluno.

- Estágios Profissionais: O hábito de estágios profissionais já nos primeiros anos dos Cursos de Direito é, em nosso País, solução tipicamente brasileira. Em nenhum outro Pais reputado pela excelência dos estudos jurídicos pode-se encontrar 
tal orientação. Neles, todo estágio se faz após o término do curso de graduação em Direito, ou, pelo menos, apenas no seu último ano. Durante o curso, a dedicação integral do aluno é aos estudos aprofundados e aos exames, vale dizer, à sólida formação acadêmica.

Aqui, vemos com tristeza e desânimo muitos bons alunos dissipando, nesses estágios, já no início do segundo ano, energia e tempo preciosos. E tudo isto com o estímulo e beneplácito de grande número de profissionais e acadêmicos do mundo jurídico.

Com tais estágios durante o curso de Direito, a Faculdade passa a ocupar posição secundária na vida desses alunos. Eles não mais estudam, quer pelo pouco interesse em comparação com a novidade e o fascínio da atividade profissional, quer, simplesmente, por falta de tempo, dada, muitas vezes, à cruel exigência do período integral por muitos dos escritórios.

Tal situação acarreta grave prejuízo para o próprio aluno, e, indiretamente, para o Brasil.

Como poderá uma desejada grande Nação formar-se a partir de levas de novos advogados que, em sua grande maioria, desprezam a formação acadêmica sendo a isso estimulados? futuro do País.

Desculpando-nos pelo exagero, parece verdadeiro atentado contra o

A exigência de boa formação constitui norma de relevante interesse público, vale dizer, norma imperativa.

O simples acordo entre um estagiário e seu escritório não deveria, pois, bastar para, sem autorização da Faculdade onde aquele estude, validar tão deletéria situação. Diante do Estatuto, visando criar uma grande Nação, tal pacto é nulo: "ius publicum privatorum pactis mutari no potest" (D. 2, 14, 38: "a norma de interesse público não pode ser modificada por acordo entre particulares").

Cabe, pois, à nossa Academia mostrar ao mundo jurídico este caminho que parece ser o melhor.

Minhas Senhoras e Meus Senhores.

A Faculdade é nossa querida "alma mater"

Diante desse fenômeno de amor pela Escola, nós, que estamos aqui dentro - atuais professores, alunos e funcionários - arcamos com enorme responsabilidade. Os que estão fora, e antigos alunos desta Casa - muitos dos quais se encontram, neste momento, aqui -, preocupam-se, de coração, com os destinos dela, conscientes de seu papel na direção das instituições do País.

Não podemos, pois, decepcioná-los e não os decepcionaremos, contando eom a colaboração de todos. Que Deus também, em sua infinita misericórdia e em testemunho de nossa fé cristã, nos ajude neste mister!

Concluindo, gostaria de renovar alguns agradecimentos. 
Primeiro, a meus queridos pais, Daisy e Wilson, e à minha querida irmã, Eliane, os três tão prematuramente afastados de meu convivio; à minha tia, primeira professora e segunda mãe, Dilze Silveira, aqui presente, a meu tio e segundo pai, Rolando de Magalhães Couto, já falecido, um dos mais cultos membros da Magistratura Bandeirante, e grande amante das Arcadas; a meus primos, nas pessoas dos queridos Mauro Marchi e Henrique Sepe; a todos os meus amigos, na pessoa de meu quaseirmão Flávio Nogueira; e, por fim, à minha querida noiva, Ana Paula Mafra.

Não poderia esquecer também os meus diletos mestres, Alexandre Augusto de Castro Corrêa e Thomas Marky, por tudo quanto fizeram e continuam a fazer por mim.

Muito Obrigado. 